DOI:10.2478/rrlm-2019-0003

\title{
An experimental in-vitro study to evaluate the anti- helicobacter activity of Glycyrrhetinic acid
}

\author{
Muhammet Murat Celik ${ }^{1}$, Nizami Duran ${ }^{2 *}$ \\ 1. Mustafa Kemal University, Medical Faculty, Department of Department of Internal Medicine, Hatay, \\ Turkey \\ 2. Mustafa Kemal University, Medical Faculty, Department of Medical Microbiology, Hatay, Turkey
}

\begin{abstract}
Aim: The aim of this study was to investigate the in-vitro efficacy of Glycyrrhetinic acid against Helicobacter pylori (H. pylori) strains, as compared with conventional antibacterial agents.

Methods: A total of $41 \mathrm{H}$. pylori isolates were used, 6 of which were of standard strains (NCTC 1637), 8 of which were drug-sensitive, and 27 were resistant to drugs isolates. Clarithromycin and metronidazole resistance in all strains of H. pylori were determined by the Epsilometer test (E-test) method. MIC study was performed by using microdilution broth method.

Results: Glycyrrhetinic acid was found to be effective against H. pylori NCTC 1637 in doses of $12.0 \pm 4.38 \mu \mathrm{g} / \mathrm{mL}$, while the MIC value of clinical H. pylori isolates susceptible to antimicrobials was $20.8 \pm 10.11 \mu \mathrm{g} / \mathrm{ml}$. It was found that the MIC values for antimicrobial-sensitive clinical H. pylori isolates was higher when compared with $H$. pylori NCTC 1637 strains. The MIC values of the standard antimicrobial agents against drug-resistant H. pylori strains were higher than H. pylori NCTC 1637 strains and drug-sensitive H. pylori strains. The MIC value was found to be $14.22 \pm 7.77 \mu \mathrm{g} / \mathrm{ml}$ for metronidazole, $3.89 \pm 1.90 \mu \mathrm{g} / \mathrm{ml}$ for clarithromycin, $2.33 \pm 1.0 \mu \mathrm{g} / \mathrm{ml}$ for amoxicillin, $2.44 \pm 0.88 \mu \mathrm{g} / \mathrm{ml}$ for levofloxacin and $4.89 \pm 2.47 \mu \mathrm{g} / \mathrm{ml}$ for tetracycline, whereas the MIC value of Glycyrrhetinic acid was $26.67 \pm 8.0 \mu \mathrm{g} / \mathrm{ml}$ in metronidazole-resistant $H$. pylori isolates. Besides, MIC values of the antimicrobials and 18ß-Glycyrrhetinic acid among the strains resistant to clarithromycin were as follows: $3.25 \pm 2.12 \mu \mathrm{g} / \mathrm{ml}$ for metronidazole, $9.71 \pm 4.54 \mu \mathrm{g} / \mathrm{ml}$ for clarithromycin, $2.06 \pm 1.32 \mu \mathrm{g} / \mathrm{ml}$ for amoxicillin, $3.88 \pm 4.22 \mu \mathrm{g} / \mathrm{ml}$ for levofloaxacin and $3.25 \pm 1.04 \mu \mathrm{g} / \mathrm{mL}$ for tetracycline and $22.0 \pm 11.11 \mu \mathrm{g} / \mathrm{ml}$ for Glycyrrhetinic acid.

Conclusion: Glycyrrhetinic acid had significant antimicrobial activity against H. pylori strains. Although further in-vivo studies are needed on antimicrobial activity of Glycyrrhetinic acid, increased resistance to drugs currently used in treatment suggests that Glycyrrhetinic acid may be a potential agent for the treatment of H. pylori.
\end{abstract}

Keywords: Glycyrrhetinic acid, Helicobacter pylori, drug, resistance, metronidazole, clarithromycin

Received: 17 th June 2018; Accepted: $3^{\text {rd }}$ November 2018; Published: $6^{\text {th }}$ January 2019

*Corresponding author: Nizami Duran, Mustafa Kemal University, Medical Faculty, Department of Medical Microbiology, Hatay, Turkey. E-mail: nizamduran@hotmail.com 


\section{Introduction}

Helicobacter pylori (H. pylori), a Gram negative curved and spiral rod, is one of the most common bacterial pathogens in humans colonized in more than half of the world's population $(1,2)$. It has been reported that the bacterium is present in almost all patients with active chronic gastritis, duodenal ulcer and gastric ulcer; thus, it may be a significant factor in the etiology of these diseases. Therefore, eradication of $H$. pylori in infected patients is very important for the treatment of diseases associated with this agent (3). For the treatment and eradication of this infectious agent, the conventional approach relies on using multiple antibiotics such as clarithromycin, amoxicillin, tetracycline, metronidazole in combination with bismuth sulphate or a proton-pump inhibitor (4). In clinical practice, $H$. pylori eradication rates vary from $60 \%$ to $80 \%$ (6). However, the resistance to antibiotics used in therapy especially to metranidazole and clarithromycin causes failure in H. pylori eradication (5). Because of treatment failures, antibiotics such as levofloxacin, rifabutin, and furazolidone have been used as alternative agents in $H$. pylori eradication. Nevertheless, both the rapid development of quinolone resistance (6) and adverse side effects related to the use of rifabutin and furazolidone have limited the effectiveness and use of these agents in the treatment of $H$. pylori infections $(7,8)$. These adversities in treatment have increased the need for the development of news agents. In addition, this also has encouraged studies investigating herbal medicinal products with antimicrobial activity as an alternative in the $H$. pylori treatment (9). It has been shown that some natural products have antibacterial activity in the treatment of $H$. pylori (10).

Licorice is the root of the Glycyrrhiza glabra. The active ingredient in licorice is glycyrrhizin (Glycyrrhizic acid, glycyrrhizinate). Glycyrrhetinic acid, a hydrolytic product of glycyrrhizic acid, is a component of licorice. Glycyrrhiza glabra, also called Licorice, is a plant belonging to Fabaceae family that is found in South Europe and some parts of Asia and has antiviral activity $(11,12)$. Animal studies on rats have shown that Licorice has significant hepatoprotective activity $(13,14)$. A study conducted by Japanese scientists found that licorice reduced transaminase levels in patients with chronic viral hepatitis (15).

Glycyrrhetinic acid major bioactive triterpene glycoside in Licorice root extracts has a wide range of pharmacological activities including anti-inflammatory, anti-ulcer, anti-allergic, antidote, anti-oxidant, anti-tumor, and antiviral effects (16). In the present study, we aimed to investigate the in-vitro efficacy of Glycyrrhetinic acid against the standard and clinical H.pylori strains as compared with conventional antibacterial agents.

\section{Material and Method}

This study used $41 \mathrm{H}$. pylori isolates, 6 of which were of standard strains (NCTC 1637), 8 of which were drug-sensitive and 27 were resistant to drugs isolates. Ethics approval for the present study was obtained from the local Ethics Committee. The experiments were carried out using the following strains: Eight susceptible strains to all antimicrobials; only metronidazole resistant (nine isolates); only clarithromycin resistant (nine isolates); both clarithromycin and metronidazole resistant strains (nine isolates); and standard H. pylori NCTC 1637 strains (six strains). Antimicrobial susceptibilities of the isolates were investigated by E-test (AB Biodisk, Sweden) method (17). The clinical samples were inoculated to Mueller-Hinton agar with 5\% sheep blood and H. pylori agar. Plates were incubated at $37^{\circ} \mathrm{C}$ in a microaerophilic environment (Camy-Gen, Oxoid). H. pylori identification was performed using conventional techniques (18.19). The standard $H$. pylori strain used in the study was supplied by the Microbiology Depart- 
ment of Hacettepe University, Medicine School in Ankara.

\section{Preparation of Bacterial Suspension}

Glycyrrhetinic acid used in the study was purchased from Sigma (18 $\beta$-Glycyrrhetinic acid, Sigma, USA). DMSO was used as solvent for Glycyrrhetinic acid. MIC values were calculated by microdilution broth method. Standard antibiotics and Glycyrrhetinic acid were diluted from 256 to $0.5 \mu \mathrm{g} / \mathrm{ml}$ by 2 -fold serial dilution.

The clinical isolates and $H$. pylori NCTC 1637 strains were suspended in Brucella Broth (BBL 4311086) containing 5\% fetal calf serum (FCS), and incubated for 48 hours at $37^{\circ} \mathrm{C}$ in microaerophilic conditions. H. pylori cell density was adjusted to $1 \times 10^{8}$ cells $/ \mathrm{ml}$. MIC values were assessed after incubation at $37^{\circ} \mathrm{C}$ under microaerophilic conditions over 5 days (20).

\section{Determination of Minimum Bactericidal Con- centration (MBC)}

Antimicrobial activity of Glycyrrhetinic acid against $H$. pylori NCTC 1637 and the clinical isolates were evaluated at the concentration of $512 \mu \mathrm{g} / \mathrm{ml}$. It was determined that Glycyrrhetinic acid inhibited the proliferation of $H$. pylori strains by $100 \%$ at this concentration. Serial dilution was performed from 512 to $0.5 \mu \mathrm{g} / \mathrm{mL}$. Bactericidal activity was studied according to the method described by O'Mahony et al. (21). Briefly, $900 \mu \mathrm{l}$ of solution containing different concentrations of Glycyrrhetinic acid were added to $100 \mu \mathrm{l}$ of bacterial suspension. At the end of the incubation, $100 \mu 1$ of each dilution were inoculated to $H$. pylori agar for evaluation of bacterial growth. Metronidazole $(100 \mu \mathrm{g} / \mathrm{ml})$, clarithromycin $(10 \mu \mathrm{g} / \mathrm{ml})$, amoxicillin $(10 \mu \mathrm{g} /$ $\mathrm{ml})$, levofloxacin $(20 \mu \mathrm{g} / \mathrm{ml})$, and tetracycline $(40 \mu \mathrm{g} / \mathrm{ml})$ were selected as the standard drugs. DMSO was used as negative control. All experiments were performed in triplicate. Bactericidal concentration was defined as the lowest concen- tration in which no growth turbidity and bacterial growth on H. pylori agar (Sigma, USA) was observed.

\section{Effect of DMSO}

In order to test the effects of DMSO against H. pylori strains and clinical H. pylori isolates, $1 \times 10^{8}$ bacterial cells were inoculated in each well of 12-well plates containing Brucella Broth medium with $5 \%$ fetal calf serum. Bacterial isolates were allowed to grow for an additional $48 \mathrm{~h}$ in the presence of decreasing amounts of DMSO ( $8 \%, 4 \%, 2 \%, 1 \%, 0.5 \%)$. The non-toxic concentration was determined up to $2 \%$. A concentration of $0.5 \%$ and $1 \%$ DMSO did not influence the growth of the $H$. pylori isolates as determined microscopically. Therefore, bacterial isolates were dissolved in $1 \%$ DMSO.

\section{Cytotoxicity Testing}

Cell Culture

HEp-2 (Human laryngeal carcinoma cell line) was used to perform cytotoxicity tests for Glycyrrhetinic acid. RPMI-1640 containing 10\% FCS, $100 \mathrm{IU} / \mathrm{ml}$ penicillin and $0.1 \mathrm{mg} / \mathrm{ml}$ streptomycin was used as the cell culture medium. DMSO $(1 \% \mathrm{v} / \mathrm{v})$ was selected as solvent to dissolve Glycyrrhetinic acid.

For cytotoxicity testing, HEp-2 cells were inoculated to microplates at a concentration of $1 \times 10^{6}$ cells $/ \mathrm{ml}$. Culture plates were incubated at $30^{\circ} \mathrm{C}$ for 8 hours for cell adhesion. At the end of the 8-hour incubation, various concentrations (3.200, 1.600, 400, 200, 100, 75, 50, $25 \mu \mathrm{g} / \mathrm{ml})$ of Glycyrrhetinic acid were added to the plates where cell adhesion was completed. Subsequently, all plates were incubated at $37^{\circ} \mathrm{C}$ with $5 \% \mathrm{CO}_{2}$ over 72 hours. All experiments were performed in triplicate.

\section{Antimicrobial Sensitivity Tests}

The presence of clarithromycin and metronidazole resistance in the clinical isolates was as- 
sessed using E-test as described by Fukazawa et al. (17). Bacteria colonies obtained from $H$. pylori cultures isolated were incubated in Mueller-Hinton agar with 7\% equine blood. The bacterial suspension was prepared in Brucella Broth according to McFarland 3 turbidity. Plates were incubated at $37^{\circ} \mathrm{C}$ over 3 days under microaerophilic conditions (CampyGen). After 3 days of incubation, antibiotic concentration corresponding to the point where the ellipsoid inhibition zone intersects the E-Test stripe was accepted as MIC value. In the present study, the following values were accepted as resistance threshold: $\geq 8$ $\mu \mathrm{g} / \mathrm{ml}$ for metronidazole and $\geq 1 \mu \mathrm{g} / \mathrm{ml}$ for clarithromycin (17).

\section{Results}

DMSO was used as solvent to prepare stock solution of Glycyrrhetinic acid. In the studies on HEp- 2 cell cultures, it was found that $1 \%$ DMSO did not inhibit cell proliferation when compared to a control group (Figure 1). There was no statistically significant difference in cell viabili- ty at 24, 48, 72 and 96 hours of incubation in cultures between the cultures containing DMSO ( $1 \% \mathrm{v} / \mathrm{w}$; DMSO control) and the cultures with neither antimicrobial agent nor DMSO (negative control).

In experiments, it was determined that Glycyrrhetinic acid was not toxic for the cells up to a concentration of $512 \mathrm{mg} / \mathrm{ml}$. There was no significant difference between the DMSO-containing group and the control group in terms of cell viability.

Moreover, in morphological evaluation by inverted microscope, it was determined that there were no pathological changes morphologically in the cell cultures containing DMSO and Glycyrrhetinic acid at concentrations up to $256 \mu \mathrm{g} /$ $\mathrm{ml}$ (including $256 \mu \mathrm{g} / \mathrm{ml}$ ) and these cells were found to be intact, like the control cells. When the Glycyrrhetinic acid concentration in the medium was used at $512 \mu \mathrm{g} / \mathrm{ml}$ and higher, cytopathological changes such as nuclear growth, rounding and granulation were observed in the cells and the cells were found to be atypical in form.

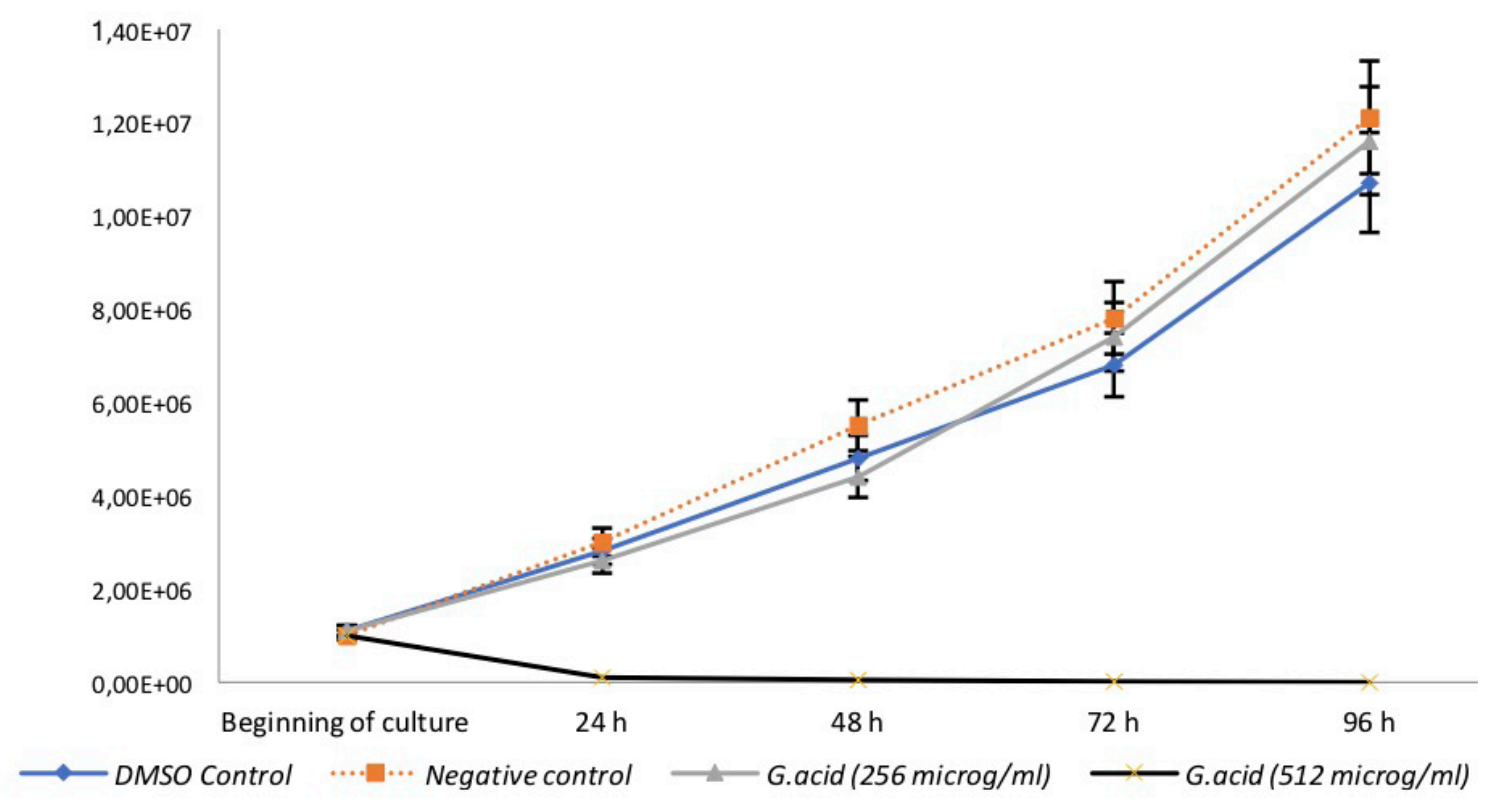

Fig. 1. The cytotoxic effect of Glycyrrhetinic acid on HEp-2 Cell line. 
The antimicrobial activity results of Glycyrrhetinic acid against $H$. pylori NCTC 1637 strain and the drug-susceptible clinical $H$. pylori isolates are shown in Figure 2. It was found that Glycyrrhetinic acid showed bactericidal activity at the $12.0 \pm 4.38 \mu \mathrm{g} / \mathrm{ml}$ for $H$. pylori NCTC 1637 , while MIC value was $20.8 \pm 10.11 \mu \mathrm{g} / \mathrm{ml}$ for the antimicrobial-sensitive clinical $H$. pylori isolates (Table 1). The MIC values of Glycyrrhetinic acid against the drug-sensitive $H$. pylori clinical isolates were found to be higher than $H$. pylori NCTC $1637(\mathrm{p}<0.01)$. When the efficacy of Glycyrrhetinic acid was compared with the commonly used antibiotics (metronidazole, clarithromycin, amoxicillin, levofloxacin, and tetracycline) for the treatment of $H$. pylori infections, the MIC value of the Glycyrrhetinic acid was found to be higher than those.

MIC value of Glycyrrhetinic acid against the metronidazole, clarithromycin-resistant and both metronidazole and clarithromycin resistant isolates were compared with the standard antimicrobial agents. Our study found that MIC values of the standard antimicrobial agents against drug-resistant $H$. pylori strains were higher when compared with those against $H$. pylori NCTC 1637 and the drug-sensitive strains $(\mathrm{p}<0.05)$. The MIC values of the antibacterials and Gly- cyrrhetinic acid against metronidazole-resistant H. pylori isolates were as follows: $14.22 \pm 7.77$ $\mu \mathrm{g} / \mathrm{ml}$ for metronidazole; $3.89 \pm 1.90 \mu \mathrm{g} / \mathrm{ml}$ for clarithromycin; $2.33 \pm 1.0 \mu \mathrm{g} / \mathrm{ml}$ for amoxicillin and levofloxacin; $2.44 \pm 0.88 \mu \mathrm{g} / \mathrm{ml}$ for tetracycline, and $4.89 \pm 2.47 \mu \mathrm{g} / \mathrm{ml}$ for Glycyrrhetinic acid (Table 1).

MIC value was found to be $3.25 \pm 2.12 \mu \mathrm{g} / \mathrm{ml}$ for metronidazole, $9.71 \pm 4.54 \mu \mathrm{g} / \mathrm{ml}$ for clarithromycin, $2.06 \pm 1.32 \mu \mathrm{g} / \mathrm{ml}$ for amoxicillin, $3.88 \pm 4.22$ $\mu \mathrm{g} / \mathrm{mL}$ for levofloxacin and $3.25 \pm 1.04 \mu \mathrm{g} / \mathrm{ml}$ for tetracycline, whereas $22.0 \pm 11.11 \mu \mathrm{g} / \mathrm{ml}$ for Glycyrrhetinic acid against the clarithromycin-resistant $H$. pylori isolates (Table 1 ).

In the $H$. pylori isolates resistant to both metronidazole and clarithromycin, the MIC values were found to be $26.88 \pm 17.30 \mu \mathrm{g} / \mathrm{ml}$ for metronidazole, $6.25 \pm 4.46 \mu \mathrm{g} / \mathrm{ml}$ for clarithromycin, $3.38 \pm 2.20 \mu \mathrm{g} / \mathrm{ml}$ for amoxicillin, $2.38 \pm 1.06 \mu \mathrm{g} /$ $\mathrm{ml}$ for levofloxacin and $4.75 \pm 2.12 \mu \mathrm{g} / \mathrm{ml}$ for tetracycline, and $37.00 \pm 18.60 \mu \mathrm{g} / \mathrm{ml}$ for Glycyrrhetinic acid.

\section{Discussion}

HP is one of the most common causes of bacterial infections in human (22). H. pylori infection is generally transmitted in childhood by

Table 1. MIC values of Glycyrrhetinic acid and antimicrobials against dug-sensitive and resistant isolates.

\begin{tabular}{lcccccc}
\hline & $\begin{array}{c}\text { Metro- } \\
\text { nidazole }\end{array}$ & $\begin{array}{c}\text { Claritro- } \\
\text { mycin }\end{array}$ & $\begin{array}{c}\text { Amoxi- } \\
\text { cillin }\end{array}$ & $\begin{array}{c}\text { Levo- } \\
\text { floxacin }\end{array}$ & $\begin{array}{c}\text { Tetra- } \\
\text { cycline }\end{array}$ & $\begin{array}{c}\text { Glycyrrhe- } \\
\text { tinic acid }\end{array}$ \\
\hline 6-H.pylori NCTC 11637 & $2.67 \pm 0.83$ & $0.75 \pm 0.27$ & $0.83 \pm 0.26$ & $2.67 \pm 1.03$ & $2.16 .0 \pm 0.98$ & $12.0 \pm 4.38$ \\
\hline $\begin{array}{l}\text { 8-Drug sensitive clinical } \\
\text { isolates }\end{array}$ & $1.05 \pm 0.55$ & $0.80 \pm 0.48$ & $0.80 \pm 0.26$ & $0.9 \pm 0.21$ & $1.8 \pm 0.92$ & $20.8 \pm 10.11$ \\
\hline $\begin{array}{l}\text { 9-Metronidazole-resis- } \\
\text { tant clinical isolates }\end{array}$ & $14.22 \pm 7.77$ & $3.89 \pm 1.90$ & $2.33 \pm 1.0$ & $2.44 \pm 0.88$ & $4.89 \pm 2.47$ & $26.67 \pm 8.0$ \\
\hline $\begin{array}{l}\text { 8-Clarithromycin-resis- } \\
\text { tant clinical isolates }\end{array}$ & $3.25 \pm 2.12$ & $9.71 \pm 4.54$ & $2.06 \pm 1.32$ & $3.88 \pm 4.22$ & $3.25 \pm 1.04$ & $22.0 \pm 11.11$ \\
\hline $\begin{array}{l}\text { 8-Both metronidazole } \\
\text { and clarithromycin re- } \\
\text { sistant isolates }\end{array}$ & $26.88 \pm 17.30$ & $6.25 \pm 4.46$ & $3.38 \pm 2.20$ & $2.38 \pm 1.06$ & $4.75 \pm 2.12$ & $37.00 \pm 18.60$ \\
\hline
\end{tabular}


"maternal-to-infant transmission". As a result of this type of transmission, multiple strains can be colonized in the stomach during childhood. The majority of these strains are eradicated spontaneously; however, a genotype adapting to the gastric mucosa and host immune system may lead to permanent colonization (23). The microorganism causes changes in gastric epithelium through direct bacterial toxicity and indirect inflammation-mediated injury (24). Several studies have found that $H$. pylori infection may be associated with chronic gastritis, peptic ulcer, gastric adenocarcinoma and pathogenesis of mucosa-related tissue lymphoma (25-29).

Although several antimicrobial agents are used effectively for the treatment of $H$. pylori, research on natural drugs has become important due to increasing antibiotic resistance in recent years. There has been an increasing popularity of medicinal plants worldwide. Studies have shown that many plants or herbal extracts can be used for the treatment of gastrointestinal system diseases. Among these plants, it is known that the roots and rhizomes of G.glabra from the family Leguminosae have been used in folk medicine for centuries. In various studies, G.glabra has been shown to have some pharmacological activities such as diuretic, laxative, sedative, antipyretic, antimicrobial, hepatoprotective, and antioxidant properties $(30,31)$.

Previous studies have shown that G.glabra has anti-allergic and anti-inflammatory activities, and that it is used for the treatment of various diseases such as allergy, asthma, and eczema. In addition, G.glabra is known to be useful for the treatment of chronic hepatitis and viral infections caused by human viruses such as human immunodeficiency virus, cytomegalovirus, and Herpes simplex virus in Japan (32-38).

In a study conducted by Kalaigandhi et al. in 2011, the activity of G.glabra against peptic ulcer caused by $H$. pylori was investigated. Ethanol and acetone extracts of G.glabra leaves were used in their study. The study reported that G.glabra had antimicrobial activity against $H$. pylori which was thought to be related to tannin, alcoholic and triterpenoid components of G.glabra (39).

Our study also found that Glycyrrhetinic acid, one of the most important components of glycyrrhiza, had a strong antimicrobial activity against H. pylori. The MIC value of Glycyrrhetinic acid against the $H$. pylori standard stain was found to be $12.0 \pm 4.38 \mu \mathrm{g} / \mathrm{ml}$ while it was found to be $20.8 \pm 10.11 \mu \mathrm{g} / \mathrm{ml}$ against the drug-sensitive $H$. pylori clinical isolates. Given the MIC value of metronidazole was $2.67 \pm 0.83 \mu \mathrm{g} / \mathrm{ml}$ against the H. pylori standard stain and $1.05 \pm 0.55 \mu \mathrm{g} / \mathrm{ml}$ for the drug sensitive clinical isolates, it was apparent that Glycyrrhetinic acid activity was significant (Figure 2). It was found that the activity of Glycyrrhetinic acid was rather high against the drug-resistant $H$. pylori strains (Figure 3). The MIC value of metronidazole was found to be $14.22 \pm 7.77 \mu \mathrm{g} / \mathrm{ml}$ against the resistant $H$. pylo$r i$ strain while the MIC value of Glycyrrhetinic acid was $26.67 \pm 8.0 \mu \mathrm{g} / \mathrm{ml}$ for the same strains. It was found that the MIC value of clarithromycin was $9.71 \pm 4.54 \mu \mathrm{g} / \mathrm{ml}$ against the clarithromycin-resistant strains while the MIC value of Glycyrrhetinic acid was $22.0 \pm 11.11 \mu \mathrm{g} / \mathrm{ml}$ for the same strain. The MIC value of Glycyrrhetinic acid was found to be $37.00 \pm 18.60 \mu \mathrm{g} / \mathrm{ml}$ for strain resistant to both clarithromycin and metronidazole, while the MIC values of metronidazole and clarithromycin for the same strains were found to be $26.88 \pm 17.30 \mu \mathrm{g} / \mathrm{ml}$ and $6.25 \pm 4.46$ $\mu \mathrm{g} / \mathrm{ml}$, respectively. In our study, we found that the MIC value of Glycyrrhetinic acid was lower against the H.pylori NCTC 1637 strain and the drug-sensitive clinical isolates, while it was increased against the drug-resistant strains.

In a randomized, placebo-controlled trial, the efficacy of Glycyrrhiza glabra extracts in patients with functional dyspepsia was investigated and $75 \mathrm{mg}$ plant extracts were given (twice 
daily for 1 month) to these patients and evaluated as comparable with the control group. When symptom severity was assessed by Likert scale, it was found that there was significant decrease in symptom severity in the patient group (40). In addition, it was shown that Glycyrrhiza glabra extracts increases gastric mucus release and has anti-ulcerative activity (41).

In an in-vitro study conducted by Asha et al. in 2013, flavonoids of Glycyrrhiza glabra were shown to be antimicrobially effective against H. pylori (42). In an in-vivo study, Wang et al. showed that it has beneficial effects on gastric mucosal damage (43).

In conclusion, it was found that Glycyrrhetinic acid had significant antimicrobial activities against the $H$. pylori strains in our study. There is a need for advanced in-vivo studies of antimicrobial activity of Glycyrrhetinic acid. Especially in recent years, resistance to drugs used in the treatment of $H$. pylori infections is a serious health problem. We think that Glycyrrhetinic acid may be a potential new agent in the treatment of diseases caused by $H$. pylori.

\section{Author statement and acknowledgements}

The second author named is lead and corresponding author. All other authors are listed in alphabetical order.

We describe contributions to the paper using the taxonomy provided above. Writing-Original Draft: M.M.C. and N.D.; Writing-Review \& Editing: M.M.C. and N.D.; Conceptualization: M.M.C. and N.D.; Investigation: M.M.C. and N.D. Methodology: M.M.C. and N.D.; Formal Analysis: M.M.C. and N.D.; Project Administration: M.M.C. and N.D.

This work was supported by the Research Fund of Mustafa Kemal University. No conflict of interest to declare.

\section{References}

1. Tonkic A, Tonkic M, Lehours P, Megraud F. Epidemiology and diagnosis of Helicobacter pylori infection. Helicobacter 2012; 17:1-8. DOI: 10.1111/j.15235378.2012.00975.x

2. Silva O, Viegas S, de Mello-Sampayo C, Costa MJ, Serrano R, Cabrita J, Gomes ET. Anti-Helicobacter pylori activity of terminalia macroptera root. Fitoterapia 2012; 83(5):872-6. DOI: 10.1016/j.fitote.2012.03.019

3. Choi JH, Yang YJ, Bang CS, Lee JJ, Baik GH. Current Status of the third-line Helicobacter pylori eradication. Gastroenterol Res Pract. 2018; 2018:6523653. DOI: $10.1155 / 2018 / 6523653$

4. Chen L, He J, Wang L, Ge Q, Chu H, Chen Y, et al. Efficacies of different proton pump inhibitor-based 14day bismuth-furazolidone quadruple regimens for the initial eradication of Helicobacter pylori in the southeast coastal region of China:an open-label, randomized clinical trial. Clin Exp Med. 2018 Jun 6. doi:10.1007/ s10238-018-0510-9. [Epub ahead of print] DOI: 10.1007/s10238-018-0510-9

5. Wu TS, Hu HM, Kuo FC, Kuo CH. Kaohsiung J. Eradication of Helicobacter pylori infection. Med Sci. 2014; 30(4):167-72. DOI: 10.1016/j.kjms.2013.11.003

6. Hu Y, Zhu Y, Lu NH. Novel and Effective Therapeutic regimens for Helicobacter pylori in an era of increasing antibiotic resistance. Front Cell Infect Microbiol. 2017; 7:168. DOI: 10.3389/fcimb.2017.00168

7. O'Connor A, Gisbert JP, McNamara D, O'Morain C. Treatment of Helicobacter pylori infection 2010. Helicobacter. 2010; Suppl 1:46-52. DOI: 10.1111/j.15235378.2010.00774.x

8. Talebi Bezmin Abadi A, Yamaoka Y. Helicobacter pylori therapy and clinical perspective. J Glob Antimicrob Resist. 2018; pii:S2213-7165(18)30057-2.

9. Amin M, Anwar F, Naz F, Mehmood T, Saari N. Anti-Helicobacter pylori and urease inhibition activities of some traditional medicinal plants. Molecules. 2013; 18(2):2135-49. DOI: 10.3390/molecules 18022135

10. Safavi M, Shams-Ardakani M, Foroumadi A. Medicinal plants in the treatment of Helicobacter pylori infections. Pharm Biol. 2015; 53(7):939-60. DOI: 10.3109/13880209.2014.952837

11. Li K, Ji S, Song W, Kuang Y, Lin Y, Tang S, et al. Glycybridins A-K, bioactive Phenolic compounds from Glycyrrhiza glabra. J Nat Prod. 2017; 80(2):334-46. DOI: 10.1021/acs.jnatprod.6b00783

12. Liu W, Sun Z, Qu J, Yang C, Zhang X, Wei X. Correlation between root respiration and the levels of biomass and glycyrrhizic acid in Glycyrrhiza uralensis. Exp Ther Med. 2017; 14(3):2323-8. DOI: $10.3892 /$ etm.2017.4723

13. Kuang Y, Lin Y, Li K, Song W, Ji S, Qiao X, et al. Screening of hepatoprotective compounds from licorice against carbon tetrachloride and acetaminophen in- 
duced HepG2 cells injury. Phytomedicine. 2017; 34:5966. DOI: 10.1016/j.phymed.2017.08.005

14. Mahmoud AM, Hussein OE, Hozayen WG, Abd ElTwab SM. Methotrexate hepatotoxicity is associated with oxidative stress, and down-regulation of PPAR $\gamma$ and Nrf2:Protective effect of 18ß-Glycyrrhetinic acid. Chem Biol Interact. 2017; 270:59-72. DOI: 10.1016/j. cbi.2017.04.009

15. Yoshida T, Abe K, Ikeda T, Matsushita T, Wake K, Sato $\mathrm{T}$, et al. Inhibitory effect of glycyrrhizin on lipopolysaccharide and d-galactosamine-induced mouse liver injury. Eur J Pharmacol. 2007; 576(1-3):136-42. DOI: 10.1016/j.ejphar.2007.08.012

16. Fujii S, Morinaga O, Uto T, Nomura S, Shoyama Y. Development of double eastern blotting for major licorice components, glycyrrhizin and liquiritin for chemical quality control of licorice using anti-glycyrrhizin and anti-liquiritin monoclonal antibodies. J Agric Food Chem. 2016; 64(5):1087-93. DOI: 10.1021/acs. jafc. 5 b0 04732

17. Fukazawa K, Seki M, Satoh K, Sugano K. Antimicrobial resistance testing of $\mathrm{H}$. pylori epsilometer test and disk diffusion test. Nihon Rinsho. 1999; 57(1):76-80.

18. Owen RJ. Baillieres Clin Gastroenterol. Bacteriology of Helicobacter pylori. 1995; 9(3):415-46.

19. Marginean OC, Stolnicu S. New diagnostic perspectives related to Helicobacter pylori infection in children. Rev Romana Med Lab, 2009; 15(2):61-8.

20. Hirschl AM, Makristathis A. Methods to detect Helicobacter pylori:from culture to molecular biology. Helicobacter. 2007; Suppl 2:6-11. DOI: 10.1111/j.15235378.2007.00560.x

21. O'Mahony R, Al-Khtheeri H, Weerasekera D, Fernando $\mathrm{N}$, Vaira D, Holton J, et al. Bactericidal and anti-adhesive properties of culinary and medicinal plants against Helicobacter pylori. World Journal of Gastroenterology 2005; 11:7499-507. DOI: 10.3748/wjg.v11.i47.7499

22. Siddique O, Ovalle A, Siddique AS, Moss SF. Helicobacter pylori Infection:An update for the internist in the age of increasing global antibiotic resistance. Am J Med. 2018; 131(5):473-9. DOI: 10.1016/j.amjmed.2017.12.024

23. Johnson KS, Ottemann KM. Colonization, localization, and inflammation:the roles of $\mathrm{H}$. pylori chemotaxis in-vivo. Curr Opin Microbiol. 2018; 41:51-7. DOI: 10.1016/j.mib.2017.11.019

24. Ford AC, Gurusamy KS, Delaney B, Forman D, Moayyedi P. Eradication therapy for peptic ulcer disease in Helicobacter pylori-positive people. Cochrane Database Syst Rev. 2016; 4:CD003840. DOI: 10.1002/14651858.CD003840.pub5

25. Zhu Y, Zhou X, Wu J, Su J, Zhang G. Risk factors and prevalence of Helicobacter pylori infection in persistent high incidence area of gastric carcinoma in yangzhong city. Gastroenterol Res Pract. 2014; 2014:481365. DOI:
$10.1155 / 2014 / 481365$

26. Pereira MI, Medeiros JA. Role of Helicobacter pylori in gastric mucosa-associated lymphoid tissue lymphomas. World J Gastroenterol. 2014; 20(3):684-98. DOI: 10.3748/wjg.v20.i3.684

27. Bornschein J, Malfertheiner P. Helicobacter pylori and gastric cancer. Dig Dis. 2014; 32(3):249-64. DOI: $10.1159 / 000357858$

28. Watari J, Chen N, Amenta PS, Fukui H, Oshima T, Tomita T, et al. Helicobacter pylori associated chronic gastritis, clinical syndromes, precancerous lesions, and pathogenesis of gastric cancer development. World J Gastroenterol. 2014; 20(18):5461-73. DOI: 10.3748/ wjg.v20.i18.5461

29. Wang F, Meng W, Wang B, Qiao L. Helicobacter pylori-induced gastric inflammation and gastric cancer. Cancer Lett. 2014; 345(2):196-202. DOI: 10.1016/j. canlet.2013.08.016

30. Nazari S, Rameshrad M, Hosseinzadeh H. Toxicological effects of Glycyrrhiza glabra (Licorice):A Review. Phytother Res. 2017; 31(11):1635-50. DOI: 10.1002/ ptr.5893

31. Hosseinzadeh H, Nassiri-Asl M. Pharmacological Effects of Glycyrrhiza spp. and Its Bioactive Constituents:Update and Review. Phytother Res. 2015; 29(12):1868-86. DOI: 10.1002/ptr.5487

32. Wei M, Ma Y, Liu Y, Zhou Y, Men L, Yue K, et al. Urinary metabolomics study on the anti-inflammation effects of flavonoids obtained from glycyrrhiza. J Chromatogr B Analyt Technol Biomed Life Sci. 2018; 1086:1-10. DOI: 10.1016/j.jchromb.2018.04.007

33. Yang N, Patil S, Zhuge J, Wen MC, Bolleddula J, Doddaga $\mathrm{S}$, et al. Glycyrrhiza uralensis flavonoids present in anti-asthma formula, ASHMI ${ }^{\mathrm{TM}}$, inhibit memory Th2 responses in vitro and in vivo. Phytother Res. 2013; 27(9):1381-91. DOI: $10.1002 /$ ptr.4862

34. Saeedi M, Morteza-Semnani K, Ghoreishi MR. The treatment of atopic dermatitis with licorice gel. J Dermatolog Treat. 2003; 14(3):153-7. DOI: 10.1080/09546630310014369

35. Fukuchi K, Okudaira N, Adachi K, Odai-Ide R, Watanabe $\mathrm{S}$, Ohno $\mathrm{H}$, et al. Antiviral and antitumor activity of licorice root extracts. In-Vivo. 2016; 30(6):777-85. DOI: 10.21873/invivo.10994

36. Pu JY, He L, Wu SY, Zhang P, Huang X. Anti-virus research of triterpenoids in licorice]. Bing Du Xue Bao. 2013; 29(6):673-9.

37. Fiore C, Eisenhut M, Krausse R, Ragazzi E, Pellati D, Armanini D, et al. Antiviral effects of glycyrrhiza species. Phytother Res. 2008; 22(2):141-8. DOI: 10.1002/ ptr.2295

38. Sabouri Ghannad M, Mohammadi A, Safiallahy S, Faradmal J, Azizi M, Ahmadvand Z. The effect of aqueous extract of glycyrrhiza glabra on Herpes simplex virus 1. Jundishapur J Microbiol. 2014; 7(7):e11616. DOI: 
$10.5812 / \mathrm{jjm} .11616$

39. Kalaigandhi V, Poovendran P, Poogunran E. Antimicrobial activity of glycyrrhiza glabra (licorice) against peptic ulcer produced Helicobacter pylori. Int J Curr Pharm Res. 2011; 3(4):93-5.

40. Raveendra KR, Jayachandra, Srinivasa V, Sushma KR, Allan JJ, Goudar KS, Shivaprasad HN, et al. An extract of Glycyrrhiza glabra (gutgard) alleviates symptoms of functional dyspepsia:a randomized, double-blind, placebo-controlled study. Evid Based Complement Alternat Med. 2012; 2012:216970. DOI: $10.1155 / 2012 / 216970$

41. Memariani Z, Hajimahmoodi M, Minaee B, Khodagholi F, Yans A, Rahimi R, et al. Protective effect of polyherbal traditional formula consisting of Rosa dam- ascena mill, Glycyrrhiza glabra L. and Nardostachys jatamansi DC., against ethanol-induced gastric ulcer. Iran J Pharm Res. 2017; 16(2):694-707.

42. Asha MK, Debraj D, Prashanth D, Edwin JR, Srikanth HS, Muruganantham N, et al. In vitro anti-Helicobacter pylori activity of a flavonoid rich extract of Glycyrrhiza glabra and its probable mechanisms of action. J Ethnopharmacol. 2013; 145(2):581-6. DOI: 10.1016/j. jep.2012.11.033

43. Wang Y, Wang S, Bao Y, Li T, Chang X, Yang G, et al. Multipathway Integrated adjustment mechanism of glycyrrhiza triterpenes curing gastric ulcer in rats. Pharmacogn Mag. 2017; 13(50):209-215. DOI: 10.4103/09731296.204550 